\title{
Deprived areas: deprived of training?
}

\author{
Mark Russell and Murray Lough
}

\section{ABSTRACT}

Health inequalities are a UK-wide health priority, but previous studies prior to expansion in GP training showed a deficit in training numbers in deprived areas. This study set out to examine whether this is still the case, using 2009 training practice data and the Scottish Index of Multiple Deprivation. Training practices were found to be significantly less deprived and significantly larger when compared with nontraining practices. Practices with training status constituted $39 \%$ of the least deprived $25 \%$ of practices, compared with $23 \%$ of the most deprived $25 \%$. The effect of deprivation persisted when practice size was taken into account.

\section{Keywords}

Education, medical; healthcare disparities; socioeconomic factors.
M Russell, MRCGP, Health Inequalities Research Fellow; M Lough, MD, FRCGP, lead (educational research), NHS Education for Scotland, Glasgow, Scotland.

Address for correspondence

Dr Mark Russell, Research Fellow, NHS Education for Scotland, 2 Central Quay, Glasgow, Scotland G3 8BW. E-mail: mark.russell@nes.scot.nhs.uk

Submitted: 4 May 2010; Editor's response: 24 May 2010; final acceptance: 11 June 2010.

(c)British Journal of General Practice 2010; 60: 846-848.

DOI: 10.3399/bjgp10X538949

\section{INTRODUCTION}

Health inequalities are a Scottish and UK government priority, ${ }^{1,2}$ but previous research indicates a relative difficulty for GP practices in recruiting and retaining doctors in some areas with high rates of deprivation. ${ }^{3}$ Deprived areas suffer from a dearth of medical staff, both absolutely and relative to their need. ${ }^{4}$

It has been suggested that GPs who are trained in areas of high deprivation are more likely to be amenable to working there, ${ }^{5}$ and that lack of experience in treating those affected by deprivation is itself a barrier to good quality care. ${ }^{6}$ If priorities with regard to improving the health of people in deprived areas are to be realised, it is therefore important to ensure that the environment within which GPs are trained is representative of the whole population served by health services.

It has previously been shown that general practice training took place in disproportionately affluent areas. ${ }^{4}$ Given the importance of general practice training systems delivering staff who can meet the needs of the population, this study set out to examine whether the large expansion in training in recent years has remedied the problem of training practices not being representative of the population with respect to deprivation.

\section{METHOD}

The study population comprised 5.46 million people and 1014 GP practices. This represents a complete national dataset, with the exception of a small number of practices, principally out-of-hours services and 'challenging patients' practices, that either have no registered patients or for whom no deprivation data were available.

The Scottish Index of Multiple Deprivation (SIMD) 2009 (version 2) was used as a measure of deprivation. SIMD ranks small areas known as datazones, with a median population of 769 , by 37 indicators across seven domains: income, employment, health, education and skills, housing, geographic access, and crime. Using these indicators, the datazones can then be ranked in order of deprivation, and the ranked list divided into population-weighted quintiles.

In this study, the Community Health Index (CHI) 
database was used to determine the postcode of every patient in each GP practice in Scotland. The postcode for each patient was then mapped to a SIMD datazone. The complete list of datazones can be ranked and divided into quintiles. Each patient can therefore be matched with the quintile to which they belong. The number of patients who fall into each quintile in a practice can then be counted. These data were produced by the NHS Information Services Division, and are publicly available. ${ }^{7}$

A deprivation score for each practice was calculated using a weighted average of the number of patients in each quintile. This gives a score for each practice, where a score of 1 represents a practice where all of the patients are in quintile 1 (least deprived), and a score of 5 represents a practice where all patients are in quintile 5 (most deprived).

Data regarding the training status of practices were obtained from NHS Education for Scotland regional offices and were accurate in August 2009.

The study tested for a significant difference between training and non-training practices with respect to the mean practice deprivation score of each group, using a two-sample $t$-test. A logistic regression model was subsequently constructed to quantify the effect of deprivation on the likelihood of training status. The data were analysed using Minitab (version 15).

\section{RESULTS}

There were 311 training practices with a mean deprivation score of 2.95 (95\% confidence interval $[\mathrm{Cl}]=2.85$ to 3.05$)$, and 703 non-training practices with a mean deprivation score of $3.19(95 \% \mathrm{Cl}=3.13$ to 3.25$)$. Training practices had a significantly lower mean deprivation score $(95 \% \mathrm{Cl}=0.13$ to 0.36 , $P<0.001$ ).

The binary logistic regression model showed that the odds of being a training practice decrease by $40 \%(95 \% \mathrm{Cl}=16 \%$ to $39 \%, P<0.001)$ with each point increase in the practice deprivation score. This effect is shown in Table 1, where all GP practices are divided into quarters by deprivation, and the number of training practices in each quarter shown.

It was noted during processing of the data that there was a discrepancy in practice size; training practices had a mean of 7394 patients $(95 \% \mathrm{Cl}=$ 7010 to 7778 patients), while non-training practices had a mean of 4519 patients $(95 \% \mathrm{Cl}=4299$ to 4739 patients). Training practices had significantly more patients $(95 \% \mathrm{Cl}=2432$ to 3319 patients, $P<0.001)$.

There was a concern that the link found could be accounted for by the difference in practice size. Practice size was introduced into the model, but the

\section{How this fits in}

Efforts have been made in Scotland during the expansion of GP training to increase the proportion of training practices that are in deprived areas. Despite this, GP training is still weighted towards more-affluent practices. This may be a concern as there is some evidence that GPs who train in deprived areas are better equipped to work there.

effect of deprivation remained significant. The odds of being a training practice decreased by $19 \%$ for a one-point increase in deprivation score $(95 \% \mathrm{Cl}=$ $3 \%$ to $32 \%, P=0.02$ ). For each extra 1000 patients a practice has, the odds of it being a training practice increased by $30 \%(95 \% \mathrm{Cl}=24 \%$ to $37 \%, P<0.001)$.

\section{DISCUSSION}

\section{Summary of main findings}

The study results show that the strong inverse association between increasing deprivation and the odds of GP practices being accredited for training continues after the expansion of GP training in recent years. This may be a concern, given the evidence of the importance of general practice training being representative of population characteristics.

\section{Strengths and limitations of the study}

The study used a measure of deprivation that has been shown to be robust. ${ }^{8,9}$ It used a method of quantifying and analysing deprivation within practices that aims to take account of all levels of deprivation within a practice, rather than merely being concerned with extremes of social inequality. Finally, the data are contemporaneous, with all data having been sourced in late 2009. This allows a judgment to be made with regard to the situation after the expansion of general practice training, and also avoids the error created by the use of deprivation indices created years prior to the study period.

The study has four potential limitations. First, it is not possible to distinguish between cause and effect. As with all observational studies, the methodology does not make it possible to determine whether practices with more-affluent patients are more likely to become training practices, or whether training

\section{Table 1. Training status by practice deprivation quintile.}

\begin{tabular}{lcc} 
& $\begin{array}{c}\text { Training practices, } \\
n\end{array}$ & $\begin{array}{c}\text { Practices with } \\
\text { training status, } \%\end{array}$ \\
\hline Least-deprived $25 \%$ of practices $(n=254)$ & 100 & 39.4 \\
\hline 2nd quintile $(n=253)$ & 83 & 32.8 \\
\hline 3rd quintile $(n=253)$ & 70 & 27.7 \\
\hline Most-deprived $25 \%$ of practices $(n=254)$ & 58 & 22.8 \\
\hline
\end{tabular}


practices are more able to attract affluent patients. It seems unlikely, however, that this latter possibility is a significant contributor to the effect found, principally because of the geographical nature of deprivation and the geographical nature of practice boundaries. Secondly, the study did not search for confounding variables. As noted in the results section, there is a link between training status and practice size, and this was shown to be a significant cofactor. However, a substantial effect remains even when practice size is taken into account. Thirdly, the object of interest is trainees' exposure, and this study looks at practices. However, the current match between ST3 trainees and training practices is close to $1: 1$, so this is very unlikely to invalidate the results. Finally, the study is only accurate to the degree with which SIMD accurately captures deprivation; it has been argued that deprivation is not unidimensional, ${ }^{10}$ either for individuals or for groups such as GP practices.

\section{Comparison with existing literature}

There are few other studies that examine GP training and social inequality. As noted in the introduction, one previous study, conducted prior to the recent expansion in GP training, of non-compulsory activities among GP surgeries in Scotland noted similar results. The present data suggest that despite the increase in the number of GP trainees and training practices in the last 5 years, postgraduate educational activity in general practice still takes place to a greater degree in more affluent areas.

\section{Implications for future research}

This research does not allow any conclusions to be made regarding the reasons behind the disparity found. This is likely to be multifactorial, and a further qualitative study may help to identify changes that could be made to facilitate the recruitment of more practices from deprived areas and make the patients experienced by GP trainees more representative of the general population.

\section{Funding body}

There was no project-specific funding. Both authors are employed by NHS Education for Scotland, which is responsible for the organisation of GP training in Scotland.

\section{Ethical approval}

\section{Not applicable.}

\section{Competing interests}

The authors have stated that there are none.

\section{Acknowledgements}

The authors wish to thank Dr Lilian Murray, senior lecturer, Faculty of Medicine, University of Glasgow, for statistical advice in connection with the preparation of this paper.

\section{Discuss this article}

Contribute and read comments about this article on the Discussion Forum: http://www.rcgp.org.uk/bjgp-discuss

\section{REFERENCES}

1. Scottish Government. Equally well: report of the ministerial task force on health inequalities. Edinburgh: Scottish Government, 2008.

2. UK Department of Health. Tackling health inequalities: 2007 status report on the programme for action. London: Department of Health, 2007.

3. Leese B, Young R, Sibbald B. Recruitment and retention of general practitioners in England: a survey of health authorities and directors of postgraduate GP education. Prim Health Care Res Dev 2002; 3: 43.

4. Mackay D, Sutton M, Watt G. Deprivation and volunteering by general practices: cross sectional analysis of a national primary care system. BMJ 2005; 331(7530): 1449-1451.

5. Harris T, Silver T, Rink E, Hilton S. Vocational training for general practice in inner London. Is there a dearth? And if so what's to be done? BMJ 1996; 312(7023): 97-101.

6. Willems SJ, Swinnen W, De Maeseneer JM. The GP's perception of poverty: a qualitative study. Fam Pract 2005; 22(2): 177-183.

7. Information Services Division, NHS National Services Scotland. Practice populations by deprivation status as at 30 September 2009. http://www.isdscotland.org/isd/6114.html (accessed 22 Sep 2010).

8, Office of the Chief Statistician, Scottish Executive. Scottish index of multiple deprivation 2006 technical report. http://www.scotland.gov.uk/Resource/Doc/933/0041180.pdf (accessed 16 Jun 2010).

9. Bishop J, Clark D, Harris V, et al. Deprivation and urban rural measurements in ISD. Summary report 2004. http://www.isdscotland.org/isd/files/Measuring_deprivation_in_IS D_v3.pdf (accessed 16 Jun 2010).

10. Nolan B, Whelan CT. Measuring deprivation. resources, deprivation and poverty. Oxford: Clarendon Press, 1996: 61. 